\title{
MOBILIDADE GEOGRÁFICA E CARREIRA: UM ESTUDO SOBRE PROFISSIONAIS QUE MIGRARAM PARA OS ESTADOS UNIDOS ${ }^{1}$
}

\author{
Tamara Cecilia Karawejczyk ${ }^{2}$
}

Para citar este artículo: Karawejczyk, T. (2016). Mobilidade geográfica e carreira: um estudo sobre profissionais que migraram para os Estados Unidos. Inquietud Empresarial. Vol. XVI (1), 117-143

Fecha de recepción: 6 de octubre de 2015

Fecha de aceptación: 24 de junio de 2016

\footnotetext{
${ }^{1}$ Este é um artigo de investigação científica e tecnológica.

${ }^{2}$ Doutora em Administração pela Universidade Federal do Rio Grande do Sul. Atualmente é professora e pesquisadora do PPG em Memória Social e Bens Culturais do Unilaalle - Canoas/RS, na linha de pesquisa Memoria e Gestão Cultural. Lider do Grupo de Pesquisa Gestão do Conhecimento, Mudança e Aprendizagem do Unilasalle/CNPQ. Atua também como docente no curso de administração e recursos humanos do Unilasalle. Tem experiência nas areas de aprendizagem e gestão do conhecimento, formação gerencial, comportamento organizacional, gestão cultural e coaching. Possui publicações nacionais e internacionais sobre estes temas. E-mail: tamara.karawejczyk@unilasalle.edu.br
} 


\section{Resumo}

Este estudo tem o intuito de investigar a mobilidade geográfica e a carreira dos profissionais que migram para os Estados Unidos. Para um melhor entendimento do assunto, as teorias relacionadas a noções de cultura e à cultura organizacional, incluindo a cultura americana, a trajetória de carreira profissional e a mobilidade geográfica oferecem o suporte necessário. O método de estudo escolhido foi o qualitativo exploratório e a técnica de análise foi a do discurso do sujeito coletivo, pois a intenção era a compreensão do todo e não a do individual. Para alcançar o objetivo, realizou-se entrevista com quinze profissionais de diferentes nacionalidades, que se enquadravam nas características da pesquisa, da empresa norte-americana Golden Gate. Como resultado desta investigação, foi categorizado em duas seções: perfil e trajetória de carreira dos entrevistados e mobilidade geográfica e trabalho nos Estados Unidos. A segunda seção permitiu a construção de seis categorias: motivos de saída do país de origem, motivos da escolha pelos Estados Unidos, conseguir emprego, dificuldades encontradas, motivos da permanência nos Estados Unidos e plano de carreira para o futuro.

Palavras chave: Mobilidade geográfica; carreira; profissionais; Estados Unidos.

\section{Movilidad geográfica y carrera: Un estudio de profesionales que emigraron a los EE.UU.}

\section{Resumen}

Este estudio tiene como objetivo investigar la movilidad geográfica y la carrera de los profesionales que emigran a los Estados Unidos. Para una mejor comprensión del tema, las teorías relacionadas con la cultura y los conceptos de cultura organizacional, incluyendo la cultura americana, trayectoria profesional y la movilidad geográfica ofrecen el apoyo necesario. El método de estudio elegido era técnica de análisis exploratorio y cualitativo fue objeto de debate público, ya que la intención era comprender el todo y no el indivíduo. Para lograr el objetivo, hubo una entrevista con quince profesionales de diferentes nacionalidades que se adapten a las características de la investigación, la firma estadounidense Golden Gate. Como resultado de esta investigación, se clasifica en dos secciones: el perfil y la trayectoria profesional de los encuestados y la movilidad geográfica y el trabajo en los Estados Unidos. La segunda sección permitió la construcción de seis categorías: el país de origen de salida razones, razones para la elección de los Estados Unidos, obtener puestos de trabajo, las dificultades encontradas, manteniendo los motivos en los Estados Unidos y plan de carrera para el futuro.

Palabras clave: Movilidad geográfica; carrera; profesionales; Estados Unidos. 


\title{
Geographic mobility and career: a study on professionals who migrate for the United States
}

\begin{abstract}
This study, aims to research the geographical mobility and the studies of the professionals who migrate to the United States. For a better understanding of the topic, the theories related to notions of culture and organizational culture, including American culture, the trajectory of career and geographic mobility provide the necessary support. The methodology of the study chosen, was qualitative exploratory and the analysis technique was the collective subject speech, because the intention was to understand the whole and not the individual. In order to achieve the goal, interviews were held with fifteen professionals of different nationalities, who fit the characteristics of the research, from the U.S. firm Golden Gate. As a result of this research, two major sections were carried out: profile and career trajectory of respondents and geographic mobility and work in the United States. The second section allowed the construction of six categories: reasons for leaving country of origin, reasons for choosing the United States, find work / employment in the United States, difficulties, reasons for staying in the U.S. and future career plans. Finally, we emphasize that this study provides opportunities for further research.
\end{abstract}

Key words: geographic mobility, career, professionals, United States.

\section{Introdução}

A globalização propiciou ao longo do tempo um novo fenômeno para o mercado de trabalho, ou seja, a possibilidade da mobilidade geográfica. Nos estudos organizacionais o fenômeno da expatriação, é um dos mais pesquisados, pois acompanha de perto os processos de internacionalização das organizações. Os estudos sobre expatriação tem sido objeto de pesquisa no meio acadêmico (Vianna e Souza, 2009; Tanure, Cyrino e Penido, 2007; Fonseca, Medeiros e Cleto, 2000; Freitas, 2000), porém a analise da mobilidade geográfica de imigrantes, é um tema recente e merecem estudos aprofundados sobre sua importância, os impactos para a vida familiar e para a carreira (Neto et al., 2010). Além disto, as diferentes culturas estão trabalhando em um mesmo contexto mercadológico, percebe-se a necessidade de entender as influências que essa realidade traz ao profissional. Desta forma pode-se ter uma ideia de como a cultura tende a influenciar a carreira profissional, trazendo influências positivas e negativas.

Entre as diversas definições para cultura, tem-se uma característica comum: a dependência de uma definição geográfica ou de uma área histórica. Os valores, Volumen XVI (1) (Enero - Diciembre 2016). ISSN 0121 - 1048 
as normas ou as crenças compartilhadas por uma sociedade pertencem a uma parte da teoria sobre cultura que existe há anos. A cultura mais temporal baseiase no significado e no comportamento do grupo analisado, como destaca Reuter (2011).

Por consequência desses fatores, a presença da multiculturalidade dentro das organizações vem aumentando. Sendo assim, essa diversidade de cultura pode gerar conflitos. Para Gelfand et al. (2010), o desafio dos gestores é conseguir administrar essa variedade. Conforme Kunda (apud Pliopas; Tonelli, 2004), existem fatores que devem ser analisados pelos gestores, como os traços culturais que afetam a gestão e a obtenção de resultados, bem como todos os comportamentos de seus funcionários. Freitas (1991) define elementos da cultura que auxiliam na interpretação e compreensão desse assunto. Acrescenta-se, assim, que esses fatores culturais resultam em diferentes intervenções na carreira dos profissionais.

A opção pela mobilidade geográfica ocasiona mudanças para o profissional, as quais impactam diretamente em suas vidas pessoais, relata Neto et al. (2010). Nesse âmbito, mostra-se que as mulheres demonstram mais resistência a mudarem de local geográfico do que os homens. Freitas (2002) alega que a escassez de trabalho e as guerras enfrentadas por alguns países estimulam a migração. Para motivar as pessoas que optam pela mobilidade geográfica é necessário que o gestor compreenda os motivos que as levaram a fazer essa escolha para suas carreiras. Ridilla (2002) ressalta que existem formas remuneradas e não remuneradas para motivar os profissionais.

Nesse contexto, o objetivo deste artigo é investigar a mobilidade geográfica e a carreira do profissional que migra para os Estados Unidos. Nesse sentido, há diferentes fatores envolvidos como: a cultura, a carreira, a mobilidade geográfica e a motivação. Assim, destaca-se a importância de compreender a influência que a cultura traz para o ser humano, bem como entender a trajetória de carreira do profissional, as dificuldades encontradas e seus planos para o futuro. Descobrir quais são as motivações que levaram o profissional a optar pela mobilidade geográfica e os motivos que fazem com que ele permaneça nos EUA também auxiliam no alcance do objetivo do presente estudo.

Para a concretização do objeto de pesquisa, escolheu-se uma empresa norteamericana de limpeza, conservação e movimentação de carros de aluguel, a Golden Gate/EUA, que se encontra em catorze cidades americanas, sendo que para este estudo foram pesquisadas as unidades de Miami, Orlando e Fort Lauderdale, as quais contratam profissionais que moram nos Estados Unidos, mas que têm sua origem em outro país. 
MOBILIDADE GEOGRÁFICA E CARREIRA: UM ESTUDO SOBRE PROFISSIONAIS QUE MIGRARAM PARA OS ESTADOS UNIDOS

\section{Referencial teórico}

Cultura é um conceito amplo para o qual existem diferentes definições. Todas as pessoas trazem consigo uma cultura enraizada, podendo ter sua origem nos seus antepassados, no local em que viveram em situações de suas vidas, entre outros. A forma de uma pessoa lidar com a sua vida, tanto pessoal como profissional, está relacionada com a cultura em que ela vive ou viveu. Tal realidade, no ambiente profissional, pode trazer problemas, pois algumas empresas estão optando pela estratégia da multiculturalidade, ou seja, várias culturas em um mesmo local. Assim, se essas organizações souberem liderar profissionais de diferentes localidades, provavelmente, terão sucesso empresarial.

Existem muitas definições para o termo "cultura", declara Reuter (2011), sendo que é uma característica comum às definições a dependência de uma definição geográfica ou de uma área histórica. $\mathrm{O}$ significado sociológico da cultura referese a valores, normas ou crenças de uma parte da sociedade que os compartilha. Com este conceito pode-se dizer que a cultura tem uma caraterística duradoura, permanece por anos.

Atrair colaboradores para a organização e retê-los é função dos gestores. Nesse sentido, Ridilla (2002) aposta na ideia de que o gestor deve fazer com que o funcionário sinta-se trabalhando em uma ótima empresa, além de tratá-lo bem. Assim, o colaborador terá vontade de ir trabalhar na organização e terá orgulho em falar para todos sobre seu serviço. Acrescenta-se que essas duas atitudes servem como fatores motivacionais aos colaboradores. No entanto, sozinhas não são o suficiente. O clima organizacional é fator importante para motivar as pessoas a optarem por trabalhar em determinada organização. Quando o funcionário se sente bem em seu ambiente de trabalho, ele desempenha melhor suas funções. Respeitar os colaboradores traz sensações de orgulho para as pessoas, acrescenta Ridilla (2002).

Gelfand et al. (2010) apresentam diferentes maneiras de lidar com a multiculturalidade, e uma delas, abordada neste estudo, é como gerenciar os conflitos resultantes da diversidade cultural. Algumas pessoas optam por lidar com o conflito de uma forma proativa, o que resulta em negociações construtivas e na resolução de problemas de uma forma colaborativa. Por outro lado, existem as pessoas que lidam de forma mais competitiva e tentam dominar o parceiro que está em conflito, acreditando que, nessas situações, se eles não vencerem, serão vencidos.

Nesse contexto, conseguir a atenção dos funcionários, fazer com que a equipe consiga estar em sintonia e compreender as coisas da mesma forma resulta em uma boa execução do trabalho. Para isso, usar estratégias criativas de 
comunicação ajuda e incentiva os colaboradores. Macdonald (2004) alega que pequenas atitudes podem fazer grande diferença para o profissional; valorizar as pessoas e preocupar-se com a vida pessoal faz com que as pessoas se sintam importantes para a empresa, contribuindo, assim, para uma boa produtividade.

Determinar metas e prioridades pode ser uma forma simples de motivar os profissionais a buscarem o sucesso. Identificar e comunicar novos comportamentos necessários para superar os desafios organizacionais geram resultados satisfatórios. Johnson (2006) menciona que ter conhecimento de algumas atividades pessoais dos profissionais ajuda na compreensão daquilo que os motiva.

Pliopas e Tonelli (2004) apresentam a entrevista realizada com Gideon Kunda, na qual ele relata que os gestores organizacionais devem prestar atenção em todos os elementos da cultura organizacional. Kunda acrescenta que há alguns fatores que devem ser analisados: os traços culturais que afetam a administração e a obtenção de resultados, bem como todos os comportamentos de seus funcionários. Freitas (1991) apresenta os elementos da cultura, que são uma forma de interpretação que os colaboradores da empresa utilizam para dar significado ao que é aceito por eles. Na medida em que eles concordam com determinada atitude organizacional, suas atitudes são refletidas pelos elementos por eles especificados. Dentre esses elementos, estão os valores, as crenças e os pressupostos, os ritos, os rituais e as cerimônias, as estórias e os mitos, os tabus, os heróis, as normas e a comunicação.

Ao realizar um estudo em uma empresa americana, cujo tema tem muita relação com a cultura, compreender um pouco sobre a cultura norte-americana auxilia no entendimento do país e no comportamento das pessoas. Além disso, com uma visão geral, é possível de se perceber algumas barreiras que trabalhadores de outros países enfrentam ao optar pela mudança.

Na entrevista de Alonso (2007), Rapaille menciona que a cultura norte-americana não tem caráter de fidelização com os produtos, ou seja, americanos provam novos produtos por gostarem do novo, do diferente. Além disso, ela é caracterizada como uma cultura jovem, muito relacionada à contínua chegada de novos imigrantes. Os norte-americanos gostam do prático, da eficiência, da rapidez e não perdem tempo com as atividades que não julgam importantes. No que se refere à qualidade das coisas, o norte-americano não costuma elogiar o que é bom. No entanto, quando tem a primeira impressão de que determinado produto ou serviço não funciona, considera-o como algo de má qualidade. 
Alguns dos elementos de estudo de Rocha (apud Pozas, 2008) relacionados a distância psicológica entre países, focado em negócios internacionais, pode ser utilizado para esse estudo. Entre os aspectos representativos, para este artigo estão: o idioma, o contexto, a maneira de ser e o relacionamento. Em relação ao idioma, a autora menciona que não ter o domínio da língua do país dificulta a relação entre as pessoas. Pozas (2008) afirma que o conhecimento do idioma é muito importante para o sucesso. Com a dificuldade da compreensão fica mais difícil das pessoas aprenderem a cultura do país.

\subsection{Trajetória de Carreira Profissional e Mobilidade Geográfica}

As facilidades de movimento existentes hoje para os profissionais fazem com que eles, assim que se depara com a insatisfação no trabalho, optem por modificar sua carreira. Nesse mesmo cenário, as organizações decidem buscar profissionais no mercado externo que possuem diferentes capacidades e habilidades. A grande movimentação de profissionais fez com que algumas empresas diminuíssem seus quadros hierárquicos. Esses fatores deram origem à carreira denominada carreira sem fronteiras. $\mathrm{O}$ dinamismo atual na carreira profissional e a instabilidade no emprego têm feito com que as pessoas se foquem mais em sua carreira pessoal. Dessa decisão resulta maior foco em suas habilidades e competências, bem como o aumento na sua empregabilidade (Direnzo e Greenhaus, 2011).

A família influencia mais na carreira da mulher do que na do homem. Essa afirmação é baseada em contextos históricos culturais, pois, na visão social, as mulheres podem naturalmente dedicar-se mais à família do que à sua carreira, nesse estágio de sua vida. Com o homem não ocorre o mesmo, já que não deixa de investir em sua carreira por causa de seu casamento e de sua família, sabendo que a mulher fará seu trabalho pela família. Países que possuem cultura masculina têm expectativas de que a carreira do homem está mais vinculada com trabalhos externos a sua casa, diferente das mulheres que se dedicam mais à família. Além disso, o perfil competitivo, duro e firme é característica masculina. Países com cultura feminina não possuem essa mesma visão. Nesses locais, não se percebe essa diferença, na medida em que os homens também se dedicam à família as mulheres têm mais oportunidades de se preocuparem com a carreira, da mesma forma que eles. Acrescenta-se que, com o passar dos anos, essa segunda tendência é vista cada vez mais, ou seja, as mulheres estão em busca de igualdade, porém com muita dificuldade (Hewlett, apud Neto et al., 2010).

No que se refere ao capital humano, Kirchmeyer, Aycan e Reinhold (apud Neto et al., 2010) relatam que historicamente homens tiveram mais oportunidade de investir em educação e em treinamento do que as mulheres. Esse investimento é 
relacionado diretamente com as maiores oportunidades de carreira que surgiram para os homens em comparação com as que surgiram para as mulheres.

O fracasso na carreira tem menor interferência para as mulheres do que para os homens, afirma Neto et al. (2010). Esse valor é muito vinculado ao nível de investimento na carreira que dos homens é maior que o das mulheres, portanto, se o sucesso não ocorrer, as consequências negativas são menores. $O$ fracasso na carreira feminina é mais aceito pelo aspecto mencionado anteriormente de que a mulher tem a preocupação de cuidar da sua família, o que ocasiona a diminuição de investimento em sua carreira, assim tornando-se uma explicação aceita ao fracasso.

Conclui-se que a grande maioria dessas diferenças entre a carreira do homem e a da mulher está relacionada com os aspectos culturais e históricos. Essas diversificações destinaram as mulheres para um estilo de vida e os homens para outro. Percebe-se que, quando há necessidade de alguma mobilidade geográfica, a mulher demonstra mais resistência, pois pensa em sua estrutura familiar. Quando o mesmo ocorre com o homem, as possibilidades dessa mudança são maiores (Neto et al., 2010).

Pessoas que optam pela mudança de localidade em suas vidas têm a tendência a alcançar maior status do que aquele que sempre viveu no mesmo lugar. A mobilidade geográfica proporciona maiores promoções na vida das pessoas (Jannuzzi, 2000). No momento em que uma pessoa se depara com a insegurança do que vai ocorrer no futuro, alguns sentimentos como desorientação, confusão e dúvida passam pelo ser humano, alega Freitas (2002).

As mudanças, com o passar dos anos, impactam também nas famílias. Freitas (2002) menciona que as mulheres adiam a decisão de ter filhos por estarem em determinado estágio profissional, ou seja, naquele momento a preferência é pelo seu trabalho. A grande mobilidade geográfica que está ocorrendo faz com que muitos filhos tenham uma criação dividida entre os pais ou, até mesmo, acabam sendo criados apenas por um deles. Com todas as mudanças que vêm ocorrendo, aquele que mais sofre as interferências é o indivíduo, sendo influenciado por todos os lados. Essas alterações causam diferentes consequências comportamentais aos seres humanos, por meio das suas atitudes diárias, da forma de lidar com sua vida, na esperança de seu futuro, no sentimento de autoconfiança, entre outros.

Nesse sentido, a organização em que o colaborador ingressar pode auxiliar nessa adaptação, utilizando algumas estratégias de motivação, como ter uma política de remuneração variável que auxilia na motivação do profissional, conforme 
constata Ridilla (2002). Fazer com que o colaborador evolua dentro da organização também estimula-o a continuar fazendo o melhor possível para seu trabalho, além de fazer com que ele se sinta sentir valorizado pelo que faz.

Segundo Macdonald (2004), quando o profissional percebe que a organização se preocupa com seu desenvolvimento de carreira, oferece oportunidades de aprendizagem e dispõe de treinamentos, ele se sente motivado a trabalhar e a desempenhar bem seu papel. Além disso, essas atitudes estimulam o profissional a querer desempenhar melhor suas funções. Na mesma linha de raciocínio de Ridilla (2002) a respeito de remuneração variável, Macdonald (2004) acrescenta que, quando as pessoas são reconhecidas pelos seus resultados, elas se motivam a melhorar seus resultados e a irem em busca dos objetivos organizacionais, bem como dos pessoais.

\section{Percurso metodológico}

Escolheu-se uma empresa norte-americana de limpeza, conservação e movimentação de carros de aluguel, Golden Gate/EUA, a qual contrata profissionais que moram nos Estados Unidos, mas que têm sua origem em outro país. Essa empresa foi a escolhida, por ser uma empresa norte-americana, primeiramente, fundada por brasileiros, e por demonstrar-se aberta à realização do estudo. Dentro de seu quadro funcional, entrevistaram-se quinze profissionais que se enquadravam nas características do estudo, sendo eles: um cubano, um libanês, um sírio, oito brasileiros, três colombianos e um haitiano. O período destinado à coleta da pesquisa foi o do mês de janeiro de 2012, sendo coletados dados em três sedes da empresa de diferentes cidades: Orlando, Miami e Fort Lauderdale. Nesse período de estudo, a pesquisadora esteve nos Estados Unidos e compreendeu algumas características dos profissionais ao realizar as entrevistas.

O método de pesquisa é de caráter qualitativo exploratório, que segundo Piovesan e Temporini (1995), tem como objetivo conhecer a variável de estudo como ela é apresentada, todo o contexto em que ela se insere, normalmente, um assunto pouco abordado, assim, abrindo espaço para pesquisas futuras. Escolheu-se como técnica de análise de estudo o discurso do sujeito coletivo, que tem como característica a pesquisa qualitativa com perguntas abertas para estimular a produção de um discurso pelo entrevistado. Ressalta-se que esse método não anula discursos, nem reduz informações; o que o discurso do sujeito coletivo pretende fazer é reconstruir um novo discurso baseado em informações individuais, no entanto, com semelhanças. Assim, utiliza-se de uma estratégia metodológica que tem por objetivo tornar mais clara um conjunto de perfis. 
Para a realização de entrevistas, elaborou-se um roteiro semiestruturado de perguntas com o intuito de investigar o entrevistado, tendo uma seção, a primeira, destinada ao perfil do candidato; a segunda referente à história de vida do entrevistado a qual contribuiu com sua trajetória de carreira, englobando motivações, objetivos, dificuldades, preparação, oportunidades; e a terceira seção relacionada à carreira profissional. Destaca-se que como limitação de estudo o fato de que, dentre as catorze cidades de atuação da empresa, entrevistaram-se apenas funcionários de três delas, a saber: Miami, Orlando e Fort Lauderdale. Outro fator limitador foi a amostra, pois foram entrevistados quinze funcionários de todo o quadro funcional.

\section{Apresentação e análise dos resultados}

Para retratar os resultados, esta seção está dividida em duas categorias: perfil e trajetória de carreira dos entrevistados e mobilidade geográfica e trabalho nos Estados Unidos.

\subsection{Perfil e Trajetória de Carreira dos Entrevistados}

Para a realização deste estudo, entrevistaram-se quinze pessoas: oito brasileiros, uma cubana, três colombianas, um haitiano, uma síria e um libanês. Com essa pequena amostra, já se pode confirmar a teoria de Rapaille (apud Alonso, 2007), a qual menciona a presença da multiculturalidade nas empresas, fator que pode favorecer a diversidade. Entre todos, há nove pessoas do gênero masculino e seis do feminino, havendo uma similaridade entre os gêneros. Os entrevistados já estão em uma fase da vida de constituição de família, pois há doze sujeitos casados e, destes, apenas dois não possuem filhos. Das outras três pessoas, duas são divorciadas, uma com filho e outra sem, e uma é solteira. 
MOBILIDADE GEOGRÁFICA E CARREIRA: UM ESTUDO SOBRE PROFISSIONAIS QUE MIGRARAM PARA OS ESTADOS UNIDOS

Tabela 1. Perfil de entrevistados.

\begin{tabular}{|c|c|c|c|c|c|}
\hline Entrevistado & Gênero & Nacionalidade & $\begin{array}{c}\text { Estado } \\
\text { civil }\end{array}$ & Filhos & $\begin{array}{c}\text { Tempo de } \\
\text { permanência } \\
\text { nos EUA }\end{array}$ \\
\hline E1 & Masculino & Brasileira & Casado & Sim & 10 anos \\
\hline E2 & Feminino & Cubana & Divorciada & Não & 4 anos \\
\hline E3 & Masculino & Brasileira & Casado & Sim & 11 anos \\
\hline E4 & Masculino & Brasileira & Casado & Sim & 10 anos \\
\hline E5 & Feminino & Brasileira & Casado & Sim & 10 anos \\
\hline E6 & Masculino & Brasileira & Casado & Sim & 6 anos \\
\hline E7 & Feminino & Colombiana & Casada & Sim & 24 anos \\
\hline E8 & Masculino & Brasileira & Casado & Não & 4 anos \\
\hline E9 & Masculino & Colombiana & Casado & Sim & 11 anos \\
\hline E10 & Masculino & Haitiana & Solteiro & Sim & 19 anos \\
\hline E11 & Masculino & Brasileira & Casado & Sim & 10 anos \\
\hline E12 & Feminino & Síria & Divorciada & Sim & 12 anos \\
\hline E13 & Feminino & Brasileira & Casada & Não & 11 anos \\
\hline E14 & Feminino & Colombiana & Casada & Sim & 7 anos \\
\hline E15 & Masculino & Libanesa & Casado & Sim & 15 anos \\
\hline
\end{tabular}

Fonte: autoria propria

\subsubsection{Mapa da trajetória}

Pela diversificação das respostas dos entrevistados, necessitou-se elaborar um mapa da trajetória da carreira dos sujeitos, pois o método do sujeito coletivo, nessa realidade, não permite uma análise adequada. Para a elaboração desse mapa, analisaram-se as respostas de todos os entrevistados, sendo separadas em duas categorias: trajetória antes e depois da mobilidade geográfica. Além disso, a categoria "depois da mobilidade geográfica", foi subdividida em: aqueles que conseguiram emprego por oportunidades que surgiram e aqueles que tiveram, em algum momento, auxílio da rede de relacionamento. 
Ilustração 1. Mapa da trajetória de carreira.

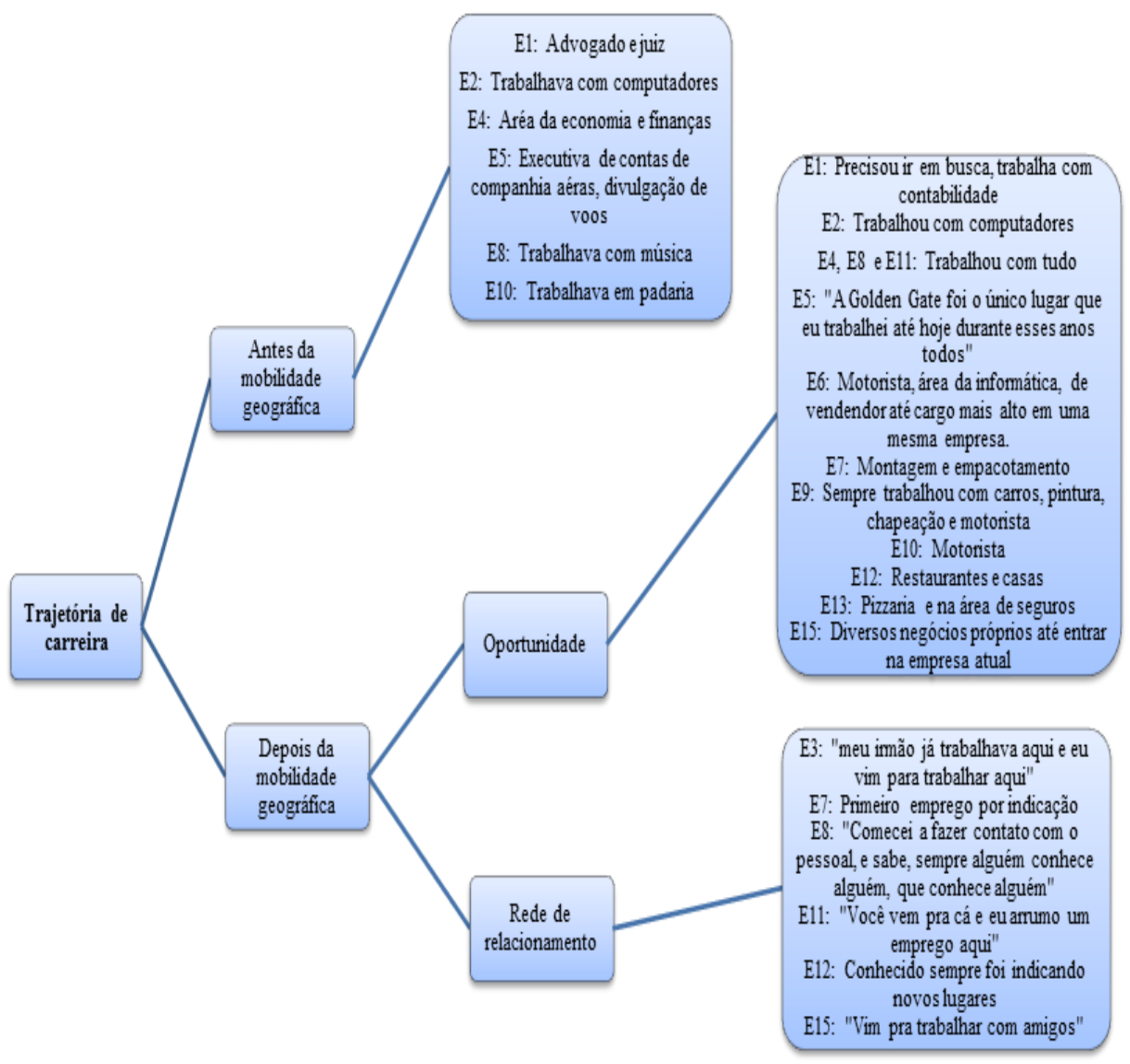

Fonte: autoria propia

Por intermédio do mapa, da Ilustração 1, é possível perceber que a maioria dos entrevistados que teve auxílio de conhecidos para conseguir emprego nos

Estados Unidos também obteve oportunidades de trabalho sem a ajuda da rede de relacionamento. Além disso, foi notório que esse auxílio foi para ingressar no mercado de trabalho no país e que, depois disso, as pessoas foram em busca de oportunidades ou essas foram surgindo. A frase "comecei a fazer contato com o pessoal, e sabe, sempre alguém conhece alguém, que conhece alguém" de um dos entrevistados deixa evidente como a rede de relacionamentos pode gerar oportunidade de trabalho. 
Com o mapa, nota-se que a maioria dos entrevistados se submeteu a trabalhos diferentes do que tinha em seu país de origem. Com essa atitude, é possível afirmar que os sujeitos aceitam mudar o caminho da sua trajetória de carreira pela vontade de mudar de país, ou ainda, que em países estrangeiros eles aceitam qualquer tipo de serviço para iniciar sua carreira, mesmo já tendo possuído cargos de maior nível em seu país de origem. Essa conclusão pode ser confirmada pela comparação de trabalhos que aparecem antes da mobilidade geográfica como o de advogado, juiz e executivo de contas com os exemplos que aparecem depois da mudança como motorista, vendedor, empacotador.

Conclui-se que aqueles que já possuíam uma carreira de trabalho antes de optarem pela mobilidade geográfica não se importam em mudar sua trajetória, diversificando o nível do cargo e, até mesmo, a área de atuação. Fica assim evidente que possuir rede de relacionamentos facilita a obtenção de serviços, mas não é a única fonte, pois há ofertas de empregos que surgem por intermédio de oportunidades. Por fim, pode-se assinalar que quem muda de país está disposto a dar origem a um novo futuro para sua carreira profissional.

\subsection{Mobilidade Geográfica e Trabalho nos Estados Unidos}

Para investigar a mobilidade geográfica e o trabalho dos migrantes nos Estados Unidos, realizou-se um conjunto de perguntas para quinze entrevistados que possuíam o perfil da pesquisa. As respostas obtidas possibilitaram a elaboração de seis categorias de análise, descritas no quadro síntese apresentado: motivos de saída do país de origem, motivos da escolha dos Estados Unidos, conseguir trabalho/emprego nos Estados Unidos, dificuldades encontradas, motivos da permanência nos Estados Unidos e plano de carreira para o futuro. Cada categoria de análise possui um conjunto de itens chaves (IC), os quais foram mencionados pelos sujeitos e auxiliam na compreensão da categoria. Após a análise dessas seis categorias, há o alcance do objetivo deste estudo.

\subsubsection{Análise dos motivos que levam a mobilidade geográfica}

Na primeira categoria encontram-se os motivos que levam os migrantes a saírem de seu país de origem. Entre os itens chaves estão à intenção de estudar, a oportunidade de trabalho no exterior, possuir rede de relacionamentos no exterior, aumentar a qualidade de vida e ir para ganhar e juntar dinheiro. Ao que se refere ao estudo, percebe-se que, praticamente, a metade dos entrevistados mencionam a vontade de estudar como um dos motivos de sua saída. 
“A intenção de ida para outro país é de estudar, além disso parentes acreditam que o estudo fora é melhor do que o do país de origem. Ter a possibilidade de aprender e poder falar o inglês, aprimorar uma segunda língua é uma motivação."

Através do DSC, percebe-se que, além da intenção de estudar fora do país, a oportunidade de aprender outra língua, que também é uma forma de estudo, é fonte de motivação. Com frase dita por um dos entrevistados "eu vim para estudar, minhas duas irmãs se mudaram para cá, ai elas queriam que eu fizesse faculdade aqui”, pode-se perceber que a mudança tem influência de pessoas que já estão residindo no país. 


\begin{tabular}{|c|c|c|c|c|c|c|c|c|c|c|c|c|c|c|c|}
\hline \multicolumn{16}{|c|}{ QUADRO SÍNTESE } \\
\hline \multirow[t]{2}{*}{ Categoria deanálise } & \multicolumn{15}{|c|}{ Entrevistados } \\
\hline & E1 & E2 & E3 & E4 & E5 & E6 & E7 & E8 & E9 & E10 & E11 & E12 & E13 & E14 & E15 \\
\hline \multicolumn{16}{|l|}{ Motivos de saída do país de origem } \\
\hline IC1: Estudar & $\mathrm{X}$ & & & $\mathrm{X}$ & $\mathrm{X}$ & $\mathrm{X}$ & & $\mathrm{X}$ & & $\mathrm{X}$ & & & $\mathrm{X}$ & & \\
\hline IC2: Oportunidade de trabalho & & $\mathrm{X}$ & $\mathrm{X}$ & $\mathrm{X}$ & $\mathrm{X}$ & $\mathrm{X}$ & & $\mathrm{X}$ & $\mathrm{X}$ & & & $\mathrm{X}$ & & $\mathrm{X}$ & $\mathrm{X}$ \\
\hline IC3: Rede de relacionamentos & & & & & & & $\mathrm{X}$ & & & & & & & & $\mathrm{X}$ \\
\hline IC4: Qualidade de vida & & & & & & & & & $\mathrm{X}$ & & $\mathrm{X}$ & & $\mathrm{X}$ & $\mathrm{X}$ & \\
\hline IC5: Dinheiro & & & & & $\mathrm{X}$ & & & & & & $\mathrm{X}$ & $\mathrm{X}$ & & & \\
\hline \multicolumn{16}{|c|}{ Motivos da escolha dos Estados Unidos } \\
\hline IC1: Estudar nos EUA & & & & $\mathrm{X}$ & & & & & & & & & $\mathrm{X}$ & & \\
\hline IC2: Oportunidade de trabalho nos EUA & $\mathrm{X}$ & & & & & & & $\mathrm{X}$ & & & & $\mathrm{X}$ & & & $\mathrm{X}$ \\
\hline IC3: Rede de Relacionamentos nos EUA & $\mathrm{X}$ & & $\mathrm{X}$ & & & & $\mathrm{X}$ & & $\mathrm{X}$ & & & & $\mathrm{X}$ & & $\mathrm{X}$ \\
\hline IC4: Cultura Americana & $\mathrm{X}$ & & & $\mathrm{X}$ & $\mathrm{X}$ & $\mathrm{X}$ & & & & & $\mathrm{X}$ & & & $\mathrm{X}$ & \\
\hline \multicolumn{16}{|c|}{ Conseguir trabalho/emprego nos Estados Unidos } \\
\hline IC1: Sem planejamento & & $\mathrm{X}$ & $\mathrm{X}$ & & $\mathrm{X}$ & & & $\mathrm{X}$ & $\mathrm{X}$ & & & $\mathrm{X}$ & $\mathrm{X}$ & & \\
\hline IC2: Com planejamento & $\mathrm{X}$ & & & $\mathrm{X}$ & & $\mathrm{X}$ & & & & $\mathrm{X}$ & $\mathrm{X}$ & & & $\mathrm{X}$ & $\mathrm{X}$ \\
\hline \multicolumn{16}{|l|}{ Dificuldades encontradas } \\
\hline IC1: Cultura e idioma & $\mathrm{X}$ & & & & $\mathrm{X}$ & & & & $\mathrm{X}$ & & $\mathrm{X}$ & $\mathrm{X}$ & $\mathrm{X}$ & & $\mathrm{X}$ \\
\hline IC2: Pessoas e solidão & $\mathrm{X}$ & & & $\mathrm{X}$ & & & $\mathrm{X}$ & & & & & & & $\mathrm{X}$ & \\
\hline IC3: Trabalho e questões legais & & $\mathrm{X}$ & $\mathrm{X}$ & & & $\mathrm{X}$ & $\mathrm{X}$ & $\mathrm{X}$ & & & & $\mathrm{X}$ & & & \\
\hline IC4: Outros & $\mathrm{X}$ & & $\mathrm{X}$ & & & & & $\mathrm{X}$ & & $\mathrm{X}$ & & & $\mathrm{X}$ & & \\
\hline \multicolumn{16}{|l|}{ Motivos da permanência nos EUA } \\
\hline IC1: Família & & & $\mathrm{X}$ & & $\mathrm{X}$ & $\mathrm{X}$ & $\mathrm{X}$ & & $\mathrm{X}$ & $\mathrm{X}$ & & & & & $\mathrm{X}$ \\
\hline IC2: Estilo de vida e cultura americana & & & & & $\mathrm{X}$ & & & & & & $\mathrm{X}$ & & $\mathrm{X}$ & $\mathrm{X}$ & \\
\hline IC3: Trabalho e estudo & $\mathrm{X}$ & $\mathrm{X}$ & & & $\mathrm{X}$ & & & $\mathrm{X}$ & & & $\mathrm{X}$ & & $\mathrm{X}$ & $\mathrm{X}$ & $\mathrm{X}$ \\
\hline \multicolumn{16}{|l|}{ Plano de carreira para o futuro } \\
\hline IC1: Voltar para o país de origen & $\mathrm{X}$ & & & $\mathrm{X}$ & & & $\mathrm{X}$ & & & & & $\mathrm{X}$ & & & \\
\hline IC2: Estudar e trabalhar & & $\mathrm{X}$ & & & & $\mathrm{X}$ & & $\mathrm{X}$ & & $\mathrm{X}$ & & & $\mathrm{X}$ & & \\
\hline IC3: Sem planos & $\mathrm{X}$ & & $\mathrm{X}$ & & $\mathrm{X}$ & & & & $\mathrm{X}$ & & $\mathrm{X}$ & & & $\mathrm{X}$ & $\mathrm{X}$ \\
\hline
\end{tabular}




\begin{abstract}
"Não poder trabalhar no país de origem, principalmente na área que agrada, motiva a saída do país, incentiva ir em busca de oportunidade de trabalho em outro país. Depois de se decepcionar com os resultados do negócio próprio, no país de origem, a solução é ir em busca de novas oportunidades. Quando há desemprego, vai-se em busca de trabalho onde há oportunidade. Fazer negócios e conseguir emprego no exterior é fácil”.
\end{abstract}

O DSC apresenta que alguns países apresentam impedimentos para algumas pessoas trabalharem naquilo que desejam, em sua área de interesse. Esse fator leva as pessoas a irem em busca de igualdades e oportunidades de trabalho. A frase de uma das entrevistadas deixa claro essa proibição e sua atitude perante isso: "lá em Cuba eu era proibida de trabalhar com isso (...) e eu vim em um barco para trabalhar aqui". A percepção de que conseguir emprego no exterior é fácil, faz com que as pessoas optem por essa mobilidade assim que encontra um obstáculo em seu país, como o desemprego, o erro nos negócios, ou, até mesmo, a ambição de melhorar sua vida profissional. Essas ideias reafirmam a teoria de Direnzo e Greenhaus (2011), a qual defende que a dinâmica na carreira mundial e a instabilidade profissional fazem as pessoas se focarem mais em sua carreira profissional, passando a existir a carreira sem fronteiras.

$\mathrm{O}$ terceiro item chave relata como a rede de relacionamentos se torna um fator motivacional para que os sujeitos optem pela mobilidade geográfica. As frases de dois dos sujeitos "eu tinha amigos aqui, então a gente foi conversando, então falaram que se eu quisesse vir pros Estados Unidos (...)" e "fiquei por aqui, pois como minha filha maior vive aqui, ela solicitou os documentos para que eu pudesse viver aqui" mostram duas realidades diferentes, na qual a rede de relacionamentos motivou a ida dos migrantes aos EUA.

Com o DSC pode-se perceber que por intermédio das redes de relacionamentos o interesse pela mobilidade geográfica pode surgir após uma visita, uma conversa, trocas de experiências, ou ainda, pode aparecer a vontade de estar próximo àquelas pessoas. Por outro lado, problemas com entes queridos no país de origem fazem com que algumas pessoas optem pela mobilidade como uma forma de fuga e de lembranças desagradáveis. A mudança de país depois do falecimento de alguma pessoa, separação conjugal ou qualquer outro tipo de briga familiar é utilizado como fonte de esquecimento, como se a pessoa quisesse apagar aquele momento triste, optando por deixar aquele país que lhe traz más lembranças.

O último item dessa categoria está relacionado ao dinheiro. Este serve de motivação para algumas pessoas optarem pela mobilidade geográfica. Nesse item, pode-se fazer uma relação com a teoria de Ridilla (2002), a qual menciona 
que a remuneração motiva as pessoas. A autora traz formas das quais a empresa pode-se utilizar para esse quesito.

"Ir morar um tempo fora, aproximadamente, seis meses, para juntar dinheiro. Conseguir ganhar dinheiro para voltar para o país de origem e conseguir pagar estudo, contas e o lazer."

O DSC desse item traz intenções de pessoas que pretenderam ganhar e juntar dinheiro com a mudança. Houve manifestações de pessoas que foram para o exterior para passar um tempo e juntar dinheiro, conforme a frase "a proposta era, dentro desses seis meses, juntar uma grana e voltar para o Brasil". Alguns têm a intenção de juntar dinheiro para pagar estudos, contas e lazer para só então retornar ao seu país. Outros não possuem a intenção de voltar. Ressalta-se que nenhum dos entrevistados optou pela mobilidade apenas com intenção de ganhar dinheiro; essa veio junto com a vontade de estudar, pela busca por oportunidade de trabalho ou pela melhoria da qualidade de vida.

Para a categoria - motivos de escolha - há quatro itens como fontes de motivação: vontade de estudar nos EUA, existência de oportunidade de trabalho nos EUA, possuir rede de relacionamentos nos EUA e a cultura americana. O primeiro item chave traz a intenção das pessoas de terem vontade de estudar nos EUA.

"Sempre se ouve falar que o estudo nos Estados Unidos é bom, sendo assim, quando o objetivo é ir atrás de bom estudo, os EUA é referência. Profissionais formados nos EUA são bem vistos, ganham boas oportunidades e tem sucesso na sua carreira."

O DSC apresenta a visão que as pessoas apresentam de os EUA ser uma referência quanto ao estudo. Além de ser um país lembrado pelo bom estudo, os sujeitos acrescentam que profissionais que tem em seu currículo alguma formação americana têm maiores chances de obterem sucesso profissional. Percebe-se que quem mencionou os estudos nessa categoria, atrelou sua escolha também à rede de relacionamento ou à cultura americana, portanto o estudo não foi o único fator decisório à mudança.

O DSC apresenta diferentes formas em que o trabalho motiva as pessoas a irem para os EUA, além do fato de alguns sujeitos possuírem facilidades por diversos motivos. Primeiramente, os EUA sempre foram visto como um país que possui oferta de trabalho, além de ter uma remuneração relativamente boa. Os EUA não é um país discriminatório, logo, não proíbe ninguém de trabalhar nas áreas que lhe agrada. Ainda relacionado ao trabalho, há pessoas que vão para fazer negócios com conhecidos. Pode-se relacionar esse DSC com a teoria de Direnzo e 
Greenhaus (2011) que relatam que as facilidades de movimentos fazem com que as pessoas modifiquem suas carreiras profissionais sempre que se deparam com as insatisfações no trabalho. Por fim, unir oportunidade de trabalho, englobando oferta e liberdade, faz a diferença na hora de optar pela escolha do país.

O terceiro item dessa categoria é a rede de relacionamentos que os sujeitos possuem nos Estados Unidos. A resposta "tenho amigos aqui, só amigos e facilidades" de um dos entrevistados, deixa claro que a rede de relacionamentos foi um dos principais motivos da escolha pelo país. Pode-se dizer que esse é um dos dois itens mais mencionados nessa categoria. Ao analisar o DSC, percebe-se a forte relação que a rede de relacionamentos tem com a escolha do país, bem como com a decisão de permanência. $\mathrm{O}$ fato de visitar algum conhecido no país influencia o sujeito a optar por aquele país, além de que o mesmo, assim, já possui referência de uma fonte segura para ele. Além disso, existe o outro lado que essas redes podem influenciar que é a vontade de estar junto com a pessoa. Tal fato, normalmente, refere-se a laços familiares, principalmente, entre filhos, pais e mães.

A cultura americana é o quarto item mencionado nessa categoria. Um dos entrevistados que escolheu os EUA pela cultura mencionou: "sempre gostei da cultura, o idioma, a facilidade de vim", ficando claro que a cultura foi um dos motivos da sua escolha. $\mathrm{O}$ item relacionado à cultura é um dos dois mais mencionados quando se questiona sobre os motivos pelas escolhas dos EUA. Por intermédio do DSC, pode-se notar que quem tem a oportunidade de ir de férias para o país norte-americano já se encanta pela cultura que presencia naquele período. Todos os fatores que envolvem a cultura, como a segurança, o respeito, a igualdade, entre outros, são quesitos que atraem os migrantes. Deve-se levar em consideração que países que não são de primeiro mundo possuem carência nesses aspectos.

Fatores relacionados a conseguir trabalho/emprego nos Estados Unidos integram a terceira categoria identificada neste estudo. Dentro dessa, há dois grandes itens: o primeiro referente àquelas pessoas que não fizeram planos; o segundo aquelas que fizeram planejamento para a sua mudança. No primeiro item chave, mencionam-se os sujeitos que não tiveram uma preparação para a sua mudança. A frase citada por um dos sujeitos deixa clara a falta de planejamento: "apareceu a oportunidade para eu vir para cá e eu nem pensei”.

"Não ir com nada programado, sem nenhuma preparação, juntar um pouco de dinheiro e ir em busca de emprego e lugar para ficar. Os Estados Unidos é um país de oportunidade, então é fácil de encontrar emprego. Em pouco tempo já se está empregado. Antigamente nem documentação 
era muito exigida, já, hoje em dia, só se consegue emprego depois de ter a documentação. Quando aparece a oportunidade não se pensa duas vezes em mudar de país. O acesso a viajar facilita a ida e aumenta as oportunidades. "

Algumas pessoas aproveitam as oportunidades que aparecem na vida para mudar de país, conforme apresentado no DSC. Juntam um pouco de dinheiro e deixam para resolver o resto quando chegam lá; a única preocupação que têm, antes de ir, é ir atrás da documentação e da passagem de avião. Como já mencionado, os EUA é visto como um país de oportunidade de emprego, então as pessoas não se preocupam em ir com algum trabalho certo quando saem de seus países, pois acreditam que irão conseguir um facilmente. A situação mencionada por uma das entrevistadas deixa clara a facilidade de conseguir emprego: "eu desembarquei às onze horas da manhã e às nove horas da noite eu já estava trabalhando". Ressaltase que nem todos conseguiram um emprego de imediato como o relato dessa situação, mas todos os entrevistados mencionaram a facilidade de encontrar emprego nos EUA. No entanto, ao decorrer do artigo, relata-se que há empregos que não deixam boas lembranças.

\subsubsection{Dificuldades encontradas}

As dificuldades encontradas com a mudança dos sujeitos é a quarta categoria deste estudo. Dentro desta, foram detectados quatro itens chaves: a cultura e o idioma, as pessoas e a solidão, o trabalho e as questões legais e outros fatores. $\mathrm{O}$ primeiro item relata a dificuldade que as pessoas enfrentam em relação à cultura americana e ao idioma. Esse item tem relação com a teoria de Schein (apud Freitas,1991), a qual traz a ideia de que para uma pessoa solucionar um problema precisa possuir as mesmas crenças e pressupostos, ou seja, a realidade e a visão precisam se equivaler. Portanto, até o sujeito se acostumar com a nova cultura, irá encontrar dificuldades. Nesse mesmo item, a teoria de Rocha (apud Pozas, 2008), que apresenta a dificuldade de relacionamento entre pessoas que não falam o mesmo idioma, condiz com a ideia dos entrevistados de que a falta de domínio do idioma do país é uma dificuldade.

Os sujeitos destacam que a diferença cultural entre o país de origem e os Estados Unidos é uma dificuldade encontrada nos primeiros momentos da mudança, pois até entenderem o sistema do país e se adaptarem ao novo demanda um tempo. Mesmo que essa cultura seja fascinante para a maioria dos migrantes, eles mencionam que toda a mudança tem suas dificuldades, portanto, pode-se concluir que mesmo sendo algo que agrada os sujeitos e até mesmo que os atrai para o país um dia já foi motivo de dificuldade. 
O quesito solidão e pessoas é o segundo item relatado pelos sujeitos como dificuldades encontradas com a mudança. Nesse quesito, pode-se relacionar o estudo de Gelfand et al. (2010), o qual menciona os conflitos que podem surgir com a diversidade cultural. Nesse estudo, os autores apresentam três diferentes formas que as pessoas lidam com o conflito: forma proativa, forma competitiva e a forma em os sujeitos evitam o conflito.

Quando o aspecto pessoas torna-se uma dificuldade para os entrevistados, como mencionado no DSC, os mesmos se referem ao fato de não saberem ao certo com que pessoas estão lidando. Essa insegurança surge de uma vantagem que os EUA proporciona a seus residentes, que é a igualdade em que todos vivem. Por esse motivo, as pessoas não sabem exatamente quem são os colegas de trabalho. Além disso, alguns sujeitos têm dificuldade de lidar com outras pessoas, portanto, quando esse contato é necessário, realizar as atividades torna-se mais difícil.

A falta de pessoas também torna-se uma dificuldade, pois a solidão começa a prejudicar a vida. A teoria de Freitas (2002) relata que o individualismo dos sujeitos tem como consequência a solidão. Nesse sentido a pesquisa apresenta que a rotina dos EUA não proporciona às pessoas a criação do hábito de encontrar os amigos; a vida acaba se fechando em um círculo menor, ou até mesmo ocasiona o individualismo. Assim, percebe-se que as pessoas acabam vivendo uma vida mais isolada, além de não terem o contato com os parentes que deixaram em seu país de origem. Viver longe dos parentes e das pessoas queridas prejudica o bem estar dos sujeitos.

O terceiro item traz as dificuldades relacionadas ao trabalho e a questões legais que os migrantes enfrentam. Frases das entrevistas exemplificam a dificuldade desses dois itens: "eu consegui um trabalho fácil, mas assim, não era um trabalho digno de se trabalhar, até antes de eu começar a trabalhar aqui" e "a maior dificuldade que encontrei aqui foi me legaliza."

"Conseguir se legalizar nos Estados Unidos é uma dificuldade, a documentação sempre foi um problema. Alguns trabalhos que as pessoas precisam se submeter para começar a carreira nos EUA são alguns dos momentos mais difíceis."

O DSC traz a ideia de que o migrante tem vontade de ficar legalizado nos Estados Unidos, no entanto, encontra dificuldade para conseguir a documentação. No mesmo sentido, quando os documentos são autorizados e os migrantes os recebem, esse passa a ser um dos momentos mais marcantes para o sujeito. A partir de então, eles possuem todos os seus direitos, inclusive entrar e sair do país 
sempre que desejarem. A documentação permite a eles serem cidadãos ou apenas ter a autorização para viver no país.

O início da carreira nos EUA, normalmente, não é lembrada como um bom momento. Quando as pessoas se mudam para um novo país, estão dispostas a encarar qualquer oportunidade que aparecer e essa atitude pode acabar se tornando uma experiência desagradável na mobilidade do sujeito. Os entrevistados mencionaram que alguns dos primeiros trabalhos que tiveram não podem ser considerados trabalhos dignos. Essa análise coincide com a pesquisa feita por Posner, Kouses e Schimidt (apud Freitas, 1991), que confirma que os profissionais ficam mais satisfeitos quando conseguem relacionar os seus valores com os da empresa, e com a teoria de Ridilla (2002), que menciona que quando há um bom clima organizacional as pessoas se motivam mais. Pode-se dizer que até as pessoas conseguirem se estabilizar profissionalmente no emprego que lhes agrada passam por dificuldades no trabalho, aceitando questões que não vão ao encontro de seus valores. Com isso, vivem, até mesmo, em um clima organizacional desagradável.

O último item dessa categoria foi elaborado para outros aspectos que foram mencionados pelos sujeitos, mas que não possuem uma denominação específica.

"Crises econômicas dificultam os negócios e prejudica as vidas. Além disso, acidentes de carros também são marcas de lembranças ruins. "

O DSC apresenta dois pontos difíceis para os sujeitos, o primeiro relacionado às crises econômicas que envolveram os Estados Unidos e que prejudicou os trabalhadores e empregadores americanos. Esse impacto econômico, gerou consequências no trabalho das pessoas, até mesmo o desemprego, causando efeito na vida dos sujeitos. O segundo são os acidentes de carros, que foi mencionado por mais de três entrevistados, podendo esses ter ocorrido com o próprio sujeito ou com algum conhecido. Esse tipo de acontecimento deixa marcas ruins na experiência de mobilidade geográfica dessas pessoas.

\subsubsection{Motivos de Permanência}

Com base nas entrevistas cedidas pelos sujeitos foi possível analisar que a grande maioria não pretende mais retornar para seu país de origem, o que se pode ser percebido com o DSC decorrente.

"Pretensão de ficar sempre nos EUA, a saída do país de origem já ocorreu com a intensão de ficar, não pode ou não quer retornar. País de origem é 
apenas um destino de viagem à passeio, passar um tempo e depois voltar aos EUA. A vida é nos EUA, onde estão as raízes e a família."

$\mathrm{O}$ primeiro item chave refere-se à família ser o motivo de permanência dos migrantes no país norte-americano. A concepção de que a família é algo muito importante para os sujeitos fica clara com o DSC. Os migrantes vão para os Estados Unidos com um conjunto de objetivos, no entanto, no decorrer dos anos esses mudam.

"A família e os filhos são motivos de permanência nos EUA. O prazer de estar com a família é maior que a vontade de sair do país. Tendo a família nos EUA não há motivos para sair de lá. O nascimento dos filhos, constituição da família, é uma das melhores coisas da vida."

Percebe-se que a maioria dos entrevistados optou pela mobilidade em um estágio de vida menos avançado, mas agora que já constituíram suas famílias a alternativa da mudança de país já não é mais avaliada como uma possibilidade. Essa conclusão pode ser explicada por dois motivos: primeiro é o fato de os sujeitos estarem satisfeitos com o país em que estão vivendo, e o segundo, especificado no DSC, é que a família os prende; criar raízes torna-se mais importante do que os outros objetivos. Ressalta-se que não houve exclusividade de gênero nessa resposta, ou seja, tanto homens quanto mulheres possuem essa preocupação familiar. Assim, pode-se confirmar a teoria de Hewlett (apud Neto et al., 2010), acrescentando que os Estados Unidos não possuem uma cultura machista, pois homens e mulheres, na mesma proporção, preocupam-se com a família e ambos possuem tempo e oportunidade para se dedicar à carreira profissional, sendo essa uma atitude de tendência mundial.

Outro item mencionado pelos sujeitos foi que o estilo de vida e a cultura americana fazem com que eles permaneçam no país. Esse DSC pode ser relacionado com o um dos resultados da pesquisa apresentada por Rodrigues (2010). Esta evidencia que o equilíbrio entre a vida profissional e pessoal é uma busca dos profissionais.

"Educar os filhos, ter segurança, conforto e qualidade de vida são fatores que levam a permanência nos EUA. A cultura do país é encantadora, o respeito com as pessoas, o modo de vida é fascinante. Recomeçar a vida do zero em outro país não motiva quando se tem a vida dos sonhos".

O segundo item refere-se a questões diretamente ligadas ao país, no entanto, percebe-se que também apareceu a preocupação com os filhos, fato relacionado com o item anterior. No DSC destaca-se que as pessoas estão satisfeitas com a vida que levam nos Estados Unidos, levando à conclusão de que essa é uma 


\section{MOBILIDADE GEOGRÁFICA E CARREIRA: UM ESTUDO SOBRE PROFISSIONAIS QUE MIGRARAM PARA OS ESTADOS UNIDOS}

caraterística específica do país, a qual condiz com as vontades dos sujeitos. Podese relacionar essa satisfação com fato de que todos os entrevistados viviam em uma realidade de países denominados de terceiro mundo e que agora estão vivendo em um país de primeiro mundo. Além disso, foi manifestado que para quem já recomeçou a vida em outro país, ou seja, quem já optou pela mobilidade geográfica, não possui mais a vontade de começar tudo de novo em outro lugar e, assim, decidem seguir a vida que têm atualmente, conforme o trecho de uma das entrevistas: "acho que não teria a mínima condição de eu começar do zero lá, então o que me faz ficar aqui é que eu já estou no meio do caminho".

Trabalho e estudo também são fatores que fazem os sujeitos permanecerem nos Estados Unidos. Com o surgimento desse item, pode-se perceber que a afirmação de Freitas (2002), referente à ideia de que a pessoa que não ir em busca de conhecimento não terá oportunidade de trabalho, foi confirmada com a pesquisa, pois essa foi uma preocupação apresentada pelos sujeitos.

"As oportunidades de estudo e de trabalho dos Estados Unidos motivam a permanência. Querer crescer no trabalho, mudar de profissão, estudar outras áreas incentivam continuar morando no país. Quando se fica legalizado nos EUA e, a partir de então, poder fazer tudo, a vontade de ficar aumenta mais."

Os mesmos motivos que fizeram alguns dos entrevistados irem aos Estados Unidos são os que fazem com que eles continuem vivendo no país. Exemplo disso é apresentado no DSC acima que os estudos e o trabalho são fatores de decisão de permanência, bem como motivadores à mudança. Percebe-se o interesse entre os entrevistados de começar a estudar novamente para iniciar uma nova profissão. $\mathrm{O}$ maior interesse em mudar de profissão está na melhoria financeira; existem determinados trabalhos nos EUA que são muito bem valorizados, mas que requerem estudos específicos. A afirmação "quero voltar a estudar, para melhorar minha carreira profissional" de um do entrevistados exemplifica essa motivação. Além disso, alguns sujeitos gostariam de dar outro foco para sua carreira por não querer mais atuar no ramo atual. A partir do momento em que as pessoas conseguem a documentação do país, torna-se mais difícil quererem retornar ao país de origem, pois começam a ter todos os direitos, principalmente, trabalho legal, como dito por uma das entrevistadas: "o que faz eu permanecer aqui é que eu já conquistei minha cidadania, eu já tenho meu direito aqui". Percebe-se que os sujeitos visam ser cidadãos americanos e que, quando o governo cede a cidadania, torna-se um marco importante na vida dos migrantes, pois esse é um processo burocrático. 


\subsubsection{Plano de carreira para o futuro}

Para entender melhor a opção de carreira dos sujeitos, elaborou-se a sexta categoria de análise relacionada ao planejamento de carreira futuro. Nessa, identificaram-se três itens chaves: voltar ao país de origem, estudar e trabalhar e aqueles que não possuem planos. $\mathrm{O}$ primeiro item chave é direcionado àqueles que têm a intenção de retornar ao país de origem para seguir sua carreira.

"Pretensão de voltar ao país de origem. Juntar dinheiro e retornar ao país é o planejamento para o futuro. Quanto antes conseguir voltar melhor é."

Com o DSC nota-se a vontade que os sujeitos possuem de retornar ao seu país, exemplificado na frase "gostaria de voltar para meu país, tenho planos para isso". Detectou-se que quatro dos entrevistados possuem essa vontade por diferentes motivos: saudades da família que ficou no outro país, não terem alcançado os objetivos que possuíam, ter encontrado muitas dificuldades. Para esses sujeitos, o maior plano é juntar dinheiro, ou se aposentar, em um caso específico, e retomar a vida que levava em seu país.

O segundo item refere que alguns dos sujeitos possuem planos de estudar e trabalhar, rapidamente mencionado na categoria anterior. Percebe-se que essa é uma preocupação trazida na teoria dos elementos da cultura de Neto et al. (2010) que menciona a preocupação com o capital humano, oportunidade de investir na educação. No entanto, não há distinção entre gêneros, como mencionado por Kirchmeyer, Aycan e Reinhold (apud Neto et al., 2010), pois tanto homens quanto mulheres possuem interesse de estudar para alavancar sua carreira profissional.

"Pro futuro a visão é ir trabalhar em outra áreas, diferente da atual. Desistir da área de atuação incentiva voltar aos estudos e mudar de área. O planejamento futuro é crescer profissionalmente, estudar mais e ganhar dinheiro."

O DSC mostra que a preocupação futura está na carreira profissional. Alguns pretendem voltar a estudar para trocar de área, ou ainda, tem aqueles que querem continuar no ramo que estão, mas querem crescer dentro da empresa. Nesse ponto a teoria de Macdonald (2004) acrescenta a ideia de que quando o profissional percebe a preocupação da empresa no desenvolvimento de sua carreira, ele se motiva mais a desempenhar suas atividades. Ressalta também que aqueles que pretendem mudar de ramo têm esse objetivo para aumentar sua renda e não necessariamente estejam insatisfeitos com o trabalho atual. Percebe-se que a 


\section{MOBILIDADE GEOGRÁFICA E CARREIRA: UM ESTUDO SOBRE PROFISSIONAIS QUE MIGRARAM PARA OS ESTADOS UNIDOS}

intenção de mudar de área leva as pessoas a voltar aos estudos e a acreditar que sem estudar dificilmente conseguirão melhorar suas carreiras profissionais.

O terceiro item dessa categoria foi definido para aqueles sujeitos que não fazem planos futuros. Como exemplo a esse item, tem-se a ideia de um dos entrevistados: "eu não gosto muito de planejar coisas muito pra frente, porque nunca da certo do jeito como que se pensa".

"Não há planos futuros, algumas coisas acontecem sem que hajam planos. A decisão de não fazer planos é por causa da falta do tempo, para não criar expectativas, por acreditar não haver necessidade e preferir que as coisas aconteçam sozinhas."

Quase a metade dos sujeitos não tem a preocupação de fazer planos futuros ou possuem muitos, mas nada em específico. Nesse sentido, o DSC mostra que são diversos os motivos que os levam a pensar dessa forma. Algumas pessoas preferem deixar as coisas acontecerem e aproveitar a oportunidade. Essa decisão pode ser explicada por decepções anteriores, ou seja, haviam muitos planos e esses não tiveram êxito, e, desse modo, preferem não criar mais expectativas. Há sujeitos que pensam que planejar não é sinônimo de bons resultados e preferem estar preparados para o que vier a acontecer do que fazer planos. Os mesmos acreditam que as coisas devem acontecer sozinhas. Alguns se demonstram dispostos a encarar novos desafios, analisam a situação que surge, e se, em sua percepção, for viável, se arriscam.

\section{Considerações finais}

Descobriu-se que estudar, busca por oportunidades de trabalho, rede de relacionamentos, melhora da qualidade de vida e dinheiro são os motivos que levam os sujeitos a saírem dos seus países de origem. Os motivos que incentivaram os entrevistados a escolherem os Estados Unidos como destino de sua mobilidade são: o estudo dos EUA, a oportunidade de trabalho existente nos EUA, rede de relacionamento nos EUA e a cultura americana. Em relação a conseguir trabalho/emprego nos EUA, há aqueles que vão sem e com planejamento. Entre as dificuldades encontradas pelos profissionais estão: cultura e idioma, pessoas e solidão, trabalho e questões legais e outros. A família, o estilo de vida e a cultura americana, o trabalho e o estudo foram mencionados como os motivos da permanência das pessoas nos país analisado. Por fim, os planos de carreira futuro são: voltar ao país de origem, estudar e trabalhar e, ainda, há sujeitos que não possuem planos. 
Além desses, a pesquisa apresentou outros resultados. Entre eles está o fato de que a maioria dos entrevistados mencionou não apenas um motivo como o impulsionador para que optassem pela mobilidade geográfica. Dentre os motivos que levaram as pessoas a escolher os Estados Unidos, os mais mencionados foram a cultura americana e possuir uma rede de relacionamento no país norteamericano. Para aqueles que se mudam, sendo com ou sem planejamento, acabam permanecendo no país por mais tempo que o previsto, ou, até mesmo, decidem residir nos EUA definitivamente. Foi diagnosticado que todos os entrevistados consideraram fácil entrar no mercado de trabalho do país norte-americano. Os fatores que motivaram a ida dos sujeitos aos Estados Unidos são os mesmos mencionados como motivos de permanência no país, destacando-se a cultura americana, o trabalho e os estudos. Por fim, como planos futuros, detectaram-se a vontade de retornar ao país de origem, os planos para o trabalho, sendo tanto mudança de área quanto crescimento organizacional, e há aqueles que não fazem planos.

\section{Referências}

Alonso, V. (2007). Aprendendo a decifrar os códigos culturais. HSM Management 60. São Paulo: HSM do Brasil, 1 (60).

Direnzo, M. y Greenhaus, J. (2011). Job search and voluntary turnover in a boundaryless world: A control theory perspective. Academy of Management Review, 36(3), pp. 567-589.

Freitas, M. (1991). "Cultura organizacional: formação, tipologias e impacto”. Makron Books do Brasil Editora Ltda. São Paulo.

Freitas, M. (2002). “Cultura organizacional: identidade, sedução e carisma? ” Editora FGV. 3. Ed. Rio de Janeiro.

Gelfand, M., Leslie, Lisa M., Keller, K., y Dedreu, C. (2010). Cultures of conflict: how leaders and members shape conflict cultures in organizations. Academy of Management Proceedings.

Jannuzzi, P. (2000). "Migração e mobilidade social: migrantes no mercado de trabalho paulista”. Campinas - SP, p. 14.

Johnson, L. (2006). Motivating employees to go above and beyond. Harvard management update. pp. 3-4.

Macdonald, B. (2004). "Organizations strain to retain high performers: Tips for motivating employees". Canadian Manager. 
Neto, A., Tanure, B., y Andrade, J. (2010). Executivas: Carreira, maternidade, amores e preconceitos. RAE - Revista de Administração de Empresas, 9 (1).

Piovesan, A., y Temporini, E. (1995). Pesquisa exploratória: procedimento metodológico para o estudo de fatores humanos no campo da saúde pública. Revista Saúde Pública, São Paulo, 29 (4)

Pozas, R. (2008). O fenômeno da distancia psicológica na percepção dos exportadores brasileiros no estabelecimento de negócios com os Estados Unidos da América. 2008. 149f Dissertação (Mestrado em Administração) - Programa de PósGraduação em Administração, Universidade do Vale do Rio dos Sinos, São Leopoldo, RS.

Reuter, C. (2011). A survey of 'culture and finance'. Revue de l'association française de finance, 32 (1).

Ridilla, P. (2002). Motivating Employees Begins With Key People. Air conditioning, heating and refrigeration news.

Rodrigues, G. (2011). Até que ponto o dinheiro motiva ou não as pessoas. Disponível em: < http://www.rhportal.com.br/artigos/wmview.php?idc_cad=nlnhfendk>. Acesso em: 5 de mai. 2011. 
